\title{
A Intertextualidade em Carlota/Amorosidade
}

\section{Geraldo Carlos do Nascimento}

Nossa leitura de Carlota/Amorosidade (1) não pretende, nem de longe, ser exaustiva. Vamos investigar a obra, se assim podemos dizer, de um ponto de vista determinado, para realçar um de seus processos de construção: a intertextualidade.

Fica evidente, mesmo para quem assistiu ao filme uma única vez, que Carlota/Amorosidade relaciona duas obras bastante conhecidas, embora bem distanciadas no tempo, Fragmentos de um Discurso Amoroso, de Roland Barthes, e Os Sofrimentos do Jovem Werther, de Goethe. Quem leu os Fragmentos, de Barthes, sabe também que o autor francês vai pinçar exatamente nesta obra de Goethe boa parte do exemplário que lhe serve de corpus para suas reflexões e comentários. Isso quer dizer que já antes do filme Barthes havia estabelecido um vínculo relacional entre as duas obras. $O$ filme, contudo, não se limita à visão de Barthes, embora, de certa forma, mantenha seu enfoque.

No filme, os textos de Barthes extraídos dos Fragmentos são proferidos pelo ator "boca" (2) e sofrem apenas algumas alterações para melhor adaptação ao discurso fílmico. Já o Werther de Goethe é, por assim dizer, traduzido ou representado cinematograficamente depois de devidamente transformado em seqüências temáticas - prólogo, prenúncio do suicídio, laboratório, estúdio fotográfico e assim por diante.

O filme de Adilson Ruiz nasce, assim, da intertextualidade explícita que mantém com essas duas obras, que constituem no dizer dos roteiristas, Maria Bacellar e Bráulio Mantovani, a substância do filme. Conhecê-las ou , pelo 
menos, ter uma noção do que elas representam culturalmente é indispensável para uma interpretação mais abrangente do filme. Essa leitura é pressuposta ou sugerida pelo autor do texto fílmico quando aponta essas obras como seus referenciais básicos. O que não quer dizer, evidentemente, que elas sejam prérequisito para toda e qualquer leitura do filme.

Mas se o espectador "comum" pode ficar liberado da operação intertextual em relação a essas duas obras, certamente não escapa de outras. A ausência de diálogos ou referências verbais, na maioria das seqüências, é preenchida por canções e músicas, em geral populares, que sugerem e dão a dimensão do clima emocional por que passa o personagem, e o leitor do texto fílmico se vê remetido a uma operação intertextual, ou seja, vai buscar apoio nas obras "indicadas" para interpretar o plano de expressão que lhe está sendo proposto. Se duvidássemos radicalmente do conteúdo da célebre frase de Bakhtin que afirma que "todo o texto se constrói como mosaico de citações, todo o texto é a absorção e transformação de um outro texto", teríamos, frente a este texto fílmico, de abrir uma exceção, pois ele se constrói explicitamente a partir de citações. (3)

Evidentemente, a leitura do filme não se esgota no reconhecimento dos signos emprestados de outras obras. O espectador tem de convertê-los em figuras, no sentido hjelmsleviano (4), que comporão o plano de expressão do discurso fílmico para realizar novas semioses. Isso exige um apagamento ou neutralização do plano de conteúdo anterior, e outros percursos de sentido podem ser desencadeados. O espectador passa a operar, agora, no universo intratextual da obra, e dependerá de seu maior ou menor grau de competência a exploração de novas isotopias.

A rigor, o discurso fílmico só é lido quando se passa para o nível intradiscursivo. Antes disso, o que a obra faz, o filme no caso, é apenas estabelecer um código ou sistema básico para sua subseqüente leitura. Nesse código, estão inclusas tacitamente toda a tradição cinematográfica, como os cortes, as técnicas de montagem, os enquadramentos, a iluminação, etc., e os "empréstimos" obtidos, via mecanismo da intertextualidade, de outras semióticas.

Em Carlota/Amorosidade a "desqualificação" dos signos obtidos via intertextualidade começa, podemos dizer, a partir da transformação dos atores. O papel actancial de Barthes nos Fragmentos, por exemplo, é conservado, mas o ator que toma o seu lugar é uma "boca vermelha" de mulher, o que é confirmado pelo timbre de sua voz. O texto proferido pela "boca" é, quase 
sempre, o de Barthes, mas não se refere mais ao texto do Werther de Goethe, e sim à sua tradução fílmica. Bastaria mudar tal relação para o sentido original se alterar. Mas não é só; nesta "tradução" outras modificações foram efetuadas: o jovem e romântico pintor Werther passa a ser um fotógrafo de moda; a pacata Carlota, una manequim descontraida. Do Werther de Gocthe conservam-se apenas o tema fundamental - o suicidio por amor - e os lances principais dos desencontros do personagem com Carlota, sempre filtrados e tematizados pela leitura de Roland Barthes.

O filme inicia-se com o percurso terminal de Werther, instantes antes de ele cometer suicídio, num flashback que não ocorre no cpistolar livro de Gocthe. A partir dai desenvolve-se uma narrativa inusitada, articulada em funçào das lembranças e devaneios do personagem, com a temporalidade marcada por uma evoluçāo sutil no relacionamento de Werther e Carlota. Os textos de Barthes, sempre proferidos pelo ator "boca", aparecem como comentários em finais de seqüência ou, ao contrário, as anunciam. O espectador atento percebe que muitos dos temas musicais, desenhos e inscrições em cartelas, como as usadas no cinema mudo, têm sempre a mesma função: traduzem para um outro código o que o iexto fímico quer dizer ou insinua.

Há seqüencias e cenas em cores e em preto e branco, e o preto e branco muitas vezes aparece com tratamento diferenciado. O que isso significa? Não é dado ao espectador mais do que reiterações para que ele tente vincular a csse conprego algum sentido. Uma hipótese, ancorada na distinção temporal pelo uso da cor presente no discurso cincmatográfico, scria pensar num tempo "real" e num tempo "inaginário". Como a narrativa tem um espaço noológico -- tudo se passa na "cabeça" de Werther pouco antes de ele acionar o gatilho --, esse tcmpo "real" teria de ser o da lembrança vivida (não cor) e o "imaginário", o tempo onirico (cor), no qual ocorreriam as "perturbaçōes" de Werther. A não cor com tratamento diferenciado revelaria um plano intermediário: o das lembranças vividas mas com alteraçōes imaginárias. ( $\mathrm{O}$ critério que adoiamos para estabclecer tal distinção foi uma maior ou menor proximidade em relação a uma semiótica do mundo natural.)

Fica evidente o investimento tímico no uso da cor; mas, contrariando nossa expectativa, a não cor é eufórica, a cor, disfórica, notadamente a cor vermelha, que è predominante. Vemelha é a "boca"; o roupão de Carlota na única cena em que Werther se aproxima fisicamente dela; a camisa que Werther escolhe para usar no momento em que vai se matar. Vermelho é o telefone. Vermelho é o sangue -- sempre sugerido, nunca realmente visto--que conota perigo. 
O branco e o preto, constituintes da não cor, no entanto, ocupam em momentos determinados dêixis diferentes, e podem ser vistos, também, como um par de opostos -- enquanto constituintes da não cor eles são complementares. Ocorre então, no nivel da manifestação, uma sobredeterminação da carga tímica. Assim, no texto fílmico, o máximo de euforia ocorre quando o branco, neutralização de todas as cores, é predominante na não cor; e o máximo de disforia acontece quando o preto, ausência total de cores, manifesta-se com o vermelho.

O exemplo mais bem acabado de tal dicotomia encontra-se na cena em que Werther toca flauta para Carlota dançar (predomínio do branco) e naquela quer Werther aparece pronto para a morte, vestido todo de preto sobre um fundo vermelho. Os temas musicais Fascinação e a ópera Werther, que durante o filme pontuam momentos eufóricos e disfóricos, tornam-se determinantes para exprimir, nos termos de Werther, o embate entre vida e morte. Para ele, que transformou a vida em sonho, a morte aparece como espetáculo. No nivel do parecer, vida e morte ficam com sinais trocados, e Tânatos triunfa.

\section{NOTAS}

(1) A motivação desta leitura decorre das fecundas sugestões apresentadas pelo professor Eduardo Peñuela Cañizal no curso "Poética da Intertextualidade Visual", ministrado na ECA/ USP, no segundo semestre de 1989. O trabalho foi apresentado no Encontro de Semiótica Literária e Outras Artes, realizado em Rio Preto, em 13 e 14 de outubro de 1989, após apresentação do filme Carlota/Amorosidade (direção de Adilson Ruiz e roteiro de Maria Bacellar e Bráulio Montovani).

(2) Uma boca focalizada em primeiro plaño, ou sua voz em off, interfere de tempos em tempos, mas sem padrão definido, no texto filmico.

(3) Apud Kristeva, Júlia, Semiótica do romance, p. 72.

(4) Prolegômenos a uma teoria da linguagem, p.51. 
(5) A temporalidade em Carlota/Amorosidade é complexa. O tempo real (sem aspas) só evolui por projeções imaginárias e o "real", não atual, dado retrospectivamente pela memória, não tem padrão definido, pois sofre interferências dos desejos de Werther

\section{BIBLIOGRAFIA}

BARTHES, R., Fragmentos de um discurso amoroso, Rio de Janeiro, Francisco Alves, 1981.

GREIMAS, A. J. e COURTÉS, J., Dicionário de semiótica, São Paulo, Cultrix, 1982.

GREIMAS, A. J., et alii, Ensaios de semiótica poética, São Paulo, Cultrix, 1975.

GOETHE; J.W. Werther, São Paulo, Abril Cultural, 1973.

HJELMSLEV, L., Prolegômenos a uma teoria da linguagem, São Paulo, Perspectiva, 1975.

KRISTEVA, J., Semiótica do romance, Lisboa, Arcádia, 1978.

LOPES, E., Discurso, texto e significação, São Paulo, Cultrix/Sec. da Cultura, Ciência e Tecnologia, 1978.

LOTMAN, Y., Estética e scmiótica do cinema, Lisboa, Estampa, 1978.

METZ, C., Linguagem e cinema, Sāo Paulo, Perspectiva, 1980. 